\title{
Avaliação da influência de amido e carragena nas características físico-químicas e sensoriais de presunto cozido de peru
}

\author{
Evaluation of the influence of starch and carrageenan on the physicochemical \\ and sensory characteristics of cooked turkey ham
}

Ricardo Alexandre PEDROSO${ }^{1}$, Ivo Mottin DEMIATE ${ }^{1 \star}$

\begin{abstract}
Resumo
Segundo a legislação brasileira, a adição de carragena em presunto é facultativa, contudo não é permitida a adição de amido neste tipo de produto. Neste trabalho, utilizou-se um planejamento fatorial $2^{2}$ com duplicata no ponto central, variando amido $(0$ a $2 \%)$ e carragena $(0$ a $1 \%)$ em presunto de peru. Tanto o amido quanto a carragena apresentaram efeitos negativos para perda por cozimento e para perda por reaquecimento, indicando que a presença destes hidrocolóides favoreceu a permanência de água nos produtos. Contudo não houve diferenças significativas de $\mathrm{pH}$ e na composição centesimal, tensão de cisalhamento e avaliação sensorial. Além disso, uma característica de sinergismo entre os polissacarídeos foi notada. Amostras elaboradas com $1 \%$ de carragena apresentaram formação de um exsudado gelatinoso, embora as amostras que continham $1 \%$ de carragena e $2 \%$ de amido não apresentaram este efeito, indicando que o amido reduz a formação de exsudado gelatinoso em presunto de peru com adição de carragena. A utilização de amido em presunto pode melhorar algumas características físicoquímicas, reduzir defeitos e não apresentar diferenças sensoriais quando comparado ao padrão brasileiro sem adição de amido.
\end{abstract}

Palavras-chave: planejamento experimental; análise sensorial; sinergismo.

\begin{abstract}
The use of carrageenan in ham is facultative, but the addition of starch is not allowed by the Brazilian legislation in this kind of product. In this work, a $2^{2}$ experimental design was used, with duplicates of the central point, considering starch ( 0 to $\left.2 \%\right)$ and carrageenan levels ( 0 to $1 \%)$ in the production of turkey ham. In both cases, starch and carrageenan showed negative effects on the purge loss and on the reheating loss, indicating that the presence of the hydrocolloids favored the retention of water in the product. However, there were no significant differences in $\mathrm{pH}$, chemical composition, shear values and in the sensory evaluation. A synergistic effect between the polysaccharides was noted. Samples made with $1 \%$ carrageenan presented the formation of a gelatinous exudate, but the samples that had $1 \%$ carrageenan and $2 \%$ starch, did not exhibit this effect. The inclusion of starch to the turkey ham with added carrageenan reduced this undesirable effect. The utilization of starch in ham improved some physicochemical characteristics, reduced defects and there were no sensory differences when the turkey ham with added starch was compared to the Brazilian standard without starch.
\end{abstract}

Keywords: experimental design; sensory analyses; synergism.

\section{Introdução}

Amido e carragena são polissacarídeos utilizados na indústria de carne, possuem boas características sensoriais, boa afinidade e preservação da água no produto, além do amido ainda ter baixo custo.

A legislação brasileira (BRASIL, 1998a) não permite a adição de amido em nenhum tipo de presunto, ao contrário de países como o Japão (KANBE et al., 1979) e os Estados Unidos (USA, 1999), cujos presuntos com alta qualidade apresentam este ingrediente em sua formulação.

A legislação brasileira permite, por meio da Portaria 1004 de 1998 (BRASIL, 1998b), uma série de polissacarídeos para utilização em produtos cárneos. $\mathrm{O}$ amido não é considerado um aditivo e não há diferenciação entre nativo e modificado.
O amido é um importante polissacarídeo adicionado em produtos cárneos, havendo uma série de vantagens em sua utilização, como seu baixo custo, tecnologia conhecida e aceitabilidade por parte dos consumidores (NABESHIMA, 1998; WURLITZER; SILVA, 1995). Além disso, por muitos anos vem sendo utilizado principalmente como espessante, sendo explorado também como estabilizante, agente de textura, ligante de água ou de gordura. $\mathrm{O}$ amido é obtido a partir de diversas fontes, principalmente cereais (milho e trigo), raízes e tubérculos (mandioca e batata).

O amido de mandioca destaca-se em relação aos demais amidos (principalmente o milho) em virtude de sua alta capacidade de retenção de água, baixa temperatura de gelatinização e por não 
apresentar odor característico de cereal (LABELL, 2004). Além disso, Lyons et al. (1999) reportam o aumento do sabor liberado durante a mastigação de produtos que contenham amido de mandioca, devido ao fato das moléculas constituintes do amido liberarem lentamente as ligações de água durante a mastigação, permitindo maior efeito de sabor e suculência do produto final.

Carragena é o nome genérico aplicado a uma categoria de hidrocolóides extraídos de algas vermelhas da classe das Rhodophyceas, sendo formada por poligalactanos, que são polímeros sulfatados de moléculas alteradas de $\mathrm{D}$-galactose e 3,6-anidro-D-galactose (3,6-AG) unidas por ligações $\alpha(1 \rightarrow 3)$ e $\beta(1 \rightarrow 4)$. O conteúdo e a distribuição dos grupos éster sulfato nestas moléculas são responsáveis pelas diferenças primárias entre os diversos tipos de carragenas, que são classificadas por kappa I, kappa II, iota e lambda (CARRAGENA, 2000).

Carragena sozinha ou combinada vem sendo amplamente usada em uma variedade de produtos cárneos, devido a sua habilidade em formar gel, reter água e fornecer textura desejada. A funcionalidade da carragena em produtos cárneos revela-se devido a sua propriedade de gelatinização térmica reversível. A carragena se dissolve totalmente no produto cárneo e se gelatiniza quando resfriada, o que aumenta a retenção de água, textura e consistência dos produtos cárneos (PIETRASIK, 2003).

\subsection{Presunto}

O padrão de identidade e qualidade de presunto (BRASIL, 2000) define-o como o produto cárneo industrializado obtido dos cortes do membro posterior de suíno, desossado ou não, adicionado de ingredientes e submetido a um processo térmico adequado. Quando o membro posterior utilizado não for de suíno, o produto será denominado de presunto, seguido do nome da espécie animal de procedência. Trata-se de um produto curado, cozido ou semicozido, defumado ou não. É permitida a adição de maltodextrina e açúcares neste produto. Proteínas não cárneas podem ser adicionadas na proporção de 1,0\% (máximo) em presunto tenro e de 2,0\% (máximo) para outros presuntos. Ainda uma relação umidade/proteína de 4,2 e 5,2 para presunto tenro e outros presuntos, respectivamente, deve ser respeitada não sendo permitida a adição de amido ou amido modificado.

O presunto, por ser um produto obtido de pernil devidamente refilado de sua gordura visível, pode conter índices de gorduras considerados baixos, quando comparado com outros produtos cárneos como mortadelas ou fiambres. Uma alternativa para a produção de um presunto com teor reduzido de gordura é a substituição do corte por membros posteriores de peru, por tratar-se de uma carne mais magra que o similar suíno (HACHMEISTER; HERALD, 1998).

Apesar do presunto não poder conter amido em sua composição, diversos outros produtos cárneos similares comumente apresentam este ingrediente, como por exemplo, apresuntados e lanches e produtos de massas finas (mortadelas e salsichas).

\section{Hidrocolóides amiláceos em presunto}

Na legislação argentina, a partir de 4 de novembro de 2002, a Comisión Permanente de Estudio y Actualización del Regula- mento de Inspección de Productos, Subproductos y Derivados de Origen Animal, não permite em presuntos, paletas e lombos, a adição de substâncias amiláceas e nem mesmo proteínas isoladas de soja (SENASA, 2005). Segundo o portal Agro Diário (AGRODIÁRIO, 2005), esta legislação foi apresentada por órgãos federais argentinos e pela Asociación Argentina de Productores de Porcinos, pois segundo esta associação, durante muitos anos a interpretação da lei antiga permitia a comercialização de presunto cozido que na realidade era uma "emulsão de amido, soja, água e um pouco de carne". Outro argumento da legislação argentina é com relação ao consumo de presunto por celíacos, pela possibilidade de presença de glúten no presunto adicionado de amido de trigo, muito comum naquele país. A legislação brasileira se apresenta bem estruturada para este tipo de ingrediente alimentar.

Nos Estados Unidos, a utilização de amido ou amido modificado é permitida em quantidade não superior a $2 \%$ do produto em uma classe de presuntos, desde que designado no rótulo "presunto com água agregada”. Contudo, segundo a Federal Register (USA, 1999) há um pedido da National Starch and Chemical Company para que se permita aumentar o nível máximo de amido de 2 para 3,5\% na formulação deste produto específico.

Kanbe et al. (1979) afirmaram que segundo a Japanese Agricultural Standard, os presuntos foram classificados em A, $\mathrm{B}, \mathrm{C}$ e D, sendo a classe $\mathrm{A}$ a de mais alto grau de qualidade, e a $\mathrm{D}$ como abaixo do grau médio. As classes $\mathrm{C}$ e $\mathrm{D}$ apresentaram quantidade de amido de até 7\%, e mesmo os níveis A e B (os mais altos níveis de qualidade de produtos japoneses) apresentaram até 3,26 e 3,86\% de amido, respectivamente.

Cai e Xue (2000), utilizando amido e uma mistura de goma xantana e kappa-carragena, constataram que para se obter a melhor qualidade durante o processamento térmico, o presunto deveria apresentar $0,6 \%$ da mistura de gomas e $9 \%$ de amido, e uma temperatura de processamento de $85^{\circ} \mathrm{C}$ por 60 minutos.

\section{Material e métodos}

\subsection{Planejamento experimental}

Para o delineamento experimental foi utilizado um planejamento fatorial 2 (AGRODIÁRIO, 2005) com duplicata no ponto central, conforme a Tabela 1 . Os gráficos e cálculos dos efeitos foram obtidos pelo emprego do programa computacional Statistica 5.0 (STATSOFT, INC.) e para a ANOVA, Microsoft Excel 2000 (Microsoft Co.).

O experimento 1 se refere ao produto elaborado com $2 \%$ de amido e $1 \%$ de carragena $(\mathrm{A}+\mathrm{C})$; o experimento 2 , ao pro-

Tabela 1. Experimento fatorial.

\begin{tabular}{lrc}
\hline \multicolumn{3}{c}{ Experimento fatorial 2 } \\
\hline \multicolumn{1}{c}{ Experimento } & Amido & Carragena \\
\hline $1(\mathrm{~A}+\mathrm{C})$ & $1(2 \%)$ & $1(1 \%)$ \\
$2(\mathrm{C})$ & $-1(0 \%)$ & $1(1 \%)$ \\
$3(\mathrm{~A})$ & $1(2 \%)$ & $-1(0 \%)$ \\
$4(\mathrm{SP})$ & $-1(0 \%)$ & $-1(0 \%)$ \\
Ponto central (PC) (5 e 6) & $0(1 \%)$ & $0(0,5 \%)$ \\
\hline
\end{tabular}


duto elaborado com $1 \%$ de carragena (C); o experimento 3, ao produto elaborado com $2 \%$ de amido (A); o experimento 4 , ao presunto de peru sem adição de polissacarídeos (SP); e o ponto central (PC) se refere ao produto elaborado com $1 \%$ de amido e $0,5 \%$ de carragena.

\subsection{Produção das amostras}

As amostras de presunto de peru foram fabricadas a partir de sobrecoxas de peru desossadas e com excesso de gordura intramuscular retirada, fornecidas pela Perdigão Agroindustrial S.A., Unidade Carambeí - PR. A carne foi espostejada de perus fêmeas de aproximadamente $15 \mathrm{~kg}$, sendo congelada até o momento de sua utilização, quando foi moída em disco de $30 \mathrm{~mm}$.

Para este experimento foram utilizados: água (35,75\%), sal refinado $(2,70 \%)$, açúcar refinado $(0,5 \%)$, antioxidante eritorbato de sódio $(0,05 \%)$, sal de cura $(0,25 \%)$, tripolifosfato $(0,5 \%)$ e condimento para presunto $(0,25 \%)$, amido de mandioca comercial e carragena comercial da marca Gelimar que apresenta uma mistura de Kappa I e Kappa II. As concentrações de amido e carragena foram apresentadas na Tabela 1.

As amostras foram produzidas na planta piloto do Centro de Tecnologia de Carnes da Empresa Perdigão Agroindustrial S.A. em Videira - SC.

A salmoura foi preparada e misturada em baldes para ser adicionada sobre a carne diretamente em Tumbler Injec Star ${ }^{\circledR}$ com capacidade para 30 litros. A etapa de tumbleamento de 2 horas e 30 minutos foi realizada sob vácuo e refrigeração, sem pausas e com aproximadamente 15 RPM. Em seguida, as amostras foram embutidas com embutideira a vácuo, em tripa de poliamida com $60 \mathrm{~mm}$ de diâmetro, grampeadas com grampeadeiras Poly-clip ${ }^{\oplus}$, numeradas e deixadas para processo de maturação sob refrigeração por 22 horas.

Após este período as peças foram mergulhadas em água a $80{ }^{\circ} \mathrm{C}$, em tanque encamisado com vapor, e mantidas até a temperatura interna da peça atingir $72{ }^{\circ} \mathrm{C}$. Em seguida, as amostras foram submetidas a banho de gelo por 2 horas para resfriamento.

A ordem de preparo foi aleatória, conforme regra do planejamento fatorial, sendo inteiramente casualizado. As amostras foram mantidas sob refrigeração até serem utilizadas nos demais testes.

\subsection{Análises da composição centesimal}

As avaliações de composição centesimal foram realizadas segundo metodologia de Lanara (1981). Foram realizadas as seguintes determinações: umidade, cinzas, proteínas, lipídios, teor de sal $(\mathrm{NaCl})$, amido, teor de nitrato e $\mathrm{pH}$. Para o amido, além do método oficial (gravimétrico), foi também usado o método empregado por Demiate, Konkel e Pedroso (2001), sem realização de diálise da amostra.

\subsection{Perda durante o resfriamento}

O material expulso durante a etapa de resfriamento foi analisado pela metodologia utilizada por Yang et al. (2001).
As amostras, de aproximadamente $800 \mathrm{~g}$, foram mantidas por 10 dias à temperatura de refrigeração, pesadas individualmente e retiradas das embalagens. As peças e as embalagens foram secas com papel absorvente, e novamente pesadas. O valor percentual é dado pela Equação 1:

$\%$ PResf $=100-[$ AS/AE - EM $] \times 100$

Sendo: \% PResf $=\%$ de perda durante o resfriamento

AS = peso da amostra seca

$\mathrm{AE}=$ peso da amostra embalada

$\mathrm{EM}=$ peso da embalagem

\subsection{Perda por reaquecimento}

A perda por reaquecimento foi determinada baseada na metodologia de Hachmeister e Herald (1998). As amostras foram cortadas em tamanhos uniformes de 2,0 $\times 2,0 \times 6,0 \mathrm{~cm}$ e pesadas. As amostras foram mergulhadas em aproximadamente $300 \mathrm{~mL}$ de água em ebulição, em béquer de $500 \mathrm{~mL}$ coberto com um vidro relógio, e mantidas por 6 minutos. Posteriormente as amostras foram escorridas em papel toalha e colocadas sob refrigeração por 6 minutos. O percentual de perda por reaquecimento foi dado pela Equação 2.

$\%$ PReaq $=[\mathrm{PF}-\mathrm{PI}] / \mathrm{PI} \times 100$

$\%$ PReaq $=\%$ perda por reaquecimento

$\mathrm{PF}=$ peso final

$\mathrm{PI}=$ peso inicial

\subsection{Textura}

Para a avaliação de textura em temperatura ambiente (aproximadamente $20^{\circ} \mathrm{C}$ ), foi utilizado um texturômetro modelo TAX.T2i (Stable Micro Systems), e foram obtidos valores de tensão de cisalhamento e compressão. Para a análise de compressão as amostras foram cortadas em pedaços de $1,5 \times 1,5 \times 2,0 \mathrm{~cm}$. Os pedaços foram comprimidos utilizando-se célula cilíndrica de $25 \mathrm{~mm}$ (P25), com distância de $10 \mathrm{~mm}$ e compressão de 66,67\%; a coleta dos dados foi realizada utilizando-se o software Texture Expert V1.19 (Stable Micro Systems), e os valores de picos máximos de compressão foram apresentados em Newton (N). O teste foi realizado com 10 repetições.

Para a avaliação da tensão de cisalhamento foram utilizadas fatias das amostras de presunto de peru de $1,5 \mathrm{~cm} \times 1,5 \mathrm{~cm} \times 4,0 \mathrm{~cm}$, e o probe utilizado foi o Warner-Bratzler Blade (HDP/BS), com uma distância de $25 \mathrm{~mm}$, efetuando o corte no sentido transversal na amostra de presunto de peru. Os valores de picos máximos de tensão de cisalhamento foram apresentados em $\mathrm{N}$, com 10 repetições.

\subsection{Cor instrumental e atividade de água}

As amostras foram analisadas em um colorímetro Minolta ${ }^{\circ}$, modelo CR400, luz D65, calibrado com padrão branco ( $\mathrm{Y}=93$; $x=0,3136$ e $y=0,3321$ ), sendo obtidos valores de $L^{*}, a^{\star} e b^{*}$. 
A atividade de água foi medida com Aqualab ${ }^{\varpi}$, modelo CX2, (Decagon Device inc.)

\subsection{Análise sensorial}

\section{Aceitabilidade}

Para avaliar a aceitabilidade dos seis produtos elaborados ( $2^{2}$ com duplicata no ponto central), utilizou-se a escala hedônica de 9 pontos, ancorada entre os pontos de mínimo e máximo: desgostei muitíssimo (1) e gostei muitíssimo (9) (ABNT, 1998). Foram utilizados 60 consumidores em potencial entre professores, funcionários e alunos de graduação e pós-graduação da Universidade Estadual de Ponta Grossa - UEPG. Amostras de presunto de peru (cubos de $1 \mathrm{~cm}$ ) foram servidas aos consumidores uma a uma em cabines individuais, e codificadas aleatoriamente com número de três dígitos, tendo sido solicitado a cada consumidor que as avaliasse quanto à impressão global, de acordo com a escala hedônica proposta.

Juntamente com a ficha de avaliação foi solicitado aos consumidores que respondessem a um questionário com a intenção de verificar o perfil dos candidatos e a freqüência de consumo de presunto de peru.

Com relação ao ponto central, por se tratar de uma duplicata, a amostra 5 (ponto central) foi servida para $50 \%$ dos provadores, e a amostra 6 (ponto central) foi servida para os outros $50 \%$ dos provadores, a fim de não causar fadiga sensorial.

Escala do ideal de cor (just right scales)

e intenção de compra

Para avaliação sensorial da cor das amostras de presunto de peru, foram utilizados 55 provadores entre professores, funcionários e alunos da Universidade Estadual de Ponta Grossa. A amostra utilizada foi aquela que obteve maior média na avaliação da aceitabilidade. Para esta avaliação foi utilizada a escala do ideal (Just Right Scales) (FERREIRA et al., 2000). Os consumidores receberam a amostra, e foi solicitado avaliá-la com relação à escala proposta, se mais clara ou mais escura que a cor ideal. O produto foi previamente cortado e disposto sob luz artificial padronizada, segundo uma escala de sete pontos com extremos: "extremamente mais escura que o ideal" até "extremamente mais clara que o ideal". Na mesma ficha, porém num segundo momento, foi solicitado aos consumidores que respondessem quanto à intenção de compra do produto apresentado. Utilizou-se uma escala de intenção de compra de 5 pontos, segundo Ferreira et al. (2000).

\section{Resultados e discussão}

\subsection{Composição centesimal}

Os resultados da composição centesimal estão descritos na Tabela 2, e como esperado mostram certa homogeneidade entre as amostras em virtude do fato de ter-se utilizado tripa impermeável, não havendo diferença de rendimento entre as amostras. Além disso, o líquido exsudado durante o processo de cozimento foi incorporado novamente ao produto e homogeneizado antes destas análises.

Os dados obtidos concordam com os de Yang et al. (2001), que avaliando oito substituintes de gordura em salsicha Frankfurt, não detectaram grandes diferenças de umidade, teor de gordura e $\mathrm{pH}$ entre os produtos.

O teor de lipídios das amostras analisadas variou de 2,39 a $3,79 \%$. Como estes valores estão próximos do limite da legislação para alimento low-fat que é de $3 \mathrm{~g} .100 \mathrm{~g}^{-1}$ de alimento (BRASIL, 1998a), os produtos serão assim considerados pois industrialmente ainda são utilizadas proteínas não cárneas (leite e soja entre outras) para produzir alimentos com baixo teor lipídico. Para este experimento a adição de proteínas não cárneas foi evitada em função dos objetivos do trabalho.

Verifica-se que as amostras produzidas se enquadram no Padrão de Identidade e Qualidade de Presunto (BRASIL, 2000), contudo algumas amostras apresentam amido em sua composição e/ou níveis de carboidratos acima da legislação, sendo que esta determina a ausência de amido e teor de carboidratos inferior a $2 \%$.

\subsection{Avaliações de pH}

As amostras de presunto de peru elaboradas com adição de amido e carragena, não apresentaram diferenças significativas ( $\mathrm{p}>0,05)$ entre si quanto ao $\mathrm{pH}$, estes dados concordam com aqueles encontrados por Pietrasik (1999) e Hamchmeister e Herald (1998).

\subsection{Perda por resfriamento e por reaquecimento}

A perda de água ou material solúvel durante o processamento de um produto cárneo é importante do ponto de vista tecno-

Tabela 2. Composição centesimal das amostras de presunto cozido de peru.

\begin{tabular}{|c|c|c|c|c|c|c|c|c|c|c|}
\hline \multirow[t]{2}{*}{ Análises } & \multicolumn{2}{|c|}{$1(\mathrm{~A}+\mathrm{C})$} & \multicolumn{2}{|c|}{$2(\mathrm{C})$} & \multicolumn{2}{|c|}{$3(\mathrm{~A})$} & \multicolumn{2}{|c|}{$4(\mathrm{SP})$} & \multicolumn{2}{|c|}{ Ponto central } \\
\hline & Média & CV \% & Média & CV\% & Média & $\mathrm{CV} \%$ & Média & $\mathrm{CV} \%$ & Média* $^{*}$ & CV\% \\
\hline Umidade (\%) & 74,06 & 0,06 & 75,76 & 0,83 & 74,93 & 0,13 & 75,85 & 0,21 & 75,49 & 0,44 \\
\hline Cinzas (\%) & 3,39 & 0,26 & 3,33 & 0,13 & 2,98 & 0,03 & 3,05 & 0,06 & 2,94 & 0,23 \\
\hline Lipídios (\%) & 3,16 & 0,06 & 3,36 & 1,14 & 2,39 & 0,06 & 2,52 & 1,77 & 3,79 & 0,58 \\
\hline Proteína (\%) & 14,65 & 0,20 & 15,24 & 0,45 & 14,89 & 0,40 & 15,78 & 0,18 & 15,25 & 0,15 \\
\hline $\mathrm{NaCl}(\%)$ & 2,43 & 0,02 & 2,21 & 0,16 & 2,12 & 0,12 & 2,06 & 0,06 & 2,09 & 0,13 \\
\hline Amido (\%) & 1,57 & 0,05 & 0,70 & 0,05 & 1,71 & 0,04 & 0,56 & 0,03 & 0,98 & 0,09 \\
\hline Nitrato (ppm) & 44,27 & 5,28 & 45,41 & 2,50 & 42,60 & 0,00 & 40,74 & 2,93 & 44,78 & 2,80 \\
\hline
\end{tabular}

*As médias são referentes a determinações em duplicata; e ${ }^{\star}$ no ponto central, média de 4 resultados de análises. 
lógico, sensorial e econômico. Esta perda pode gerar acúmulo de líquidos em embalagens, causando má impressão ao consumidor. Além disso, produtos como presunto são geralmente retirados da embalagem primária e fatiados no supermercado, causando prejuízos ao fatiador devido à perda de massa.

Para presuntos que serão utilizados como matéria-prima de outros pratos, como pizzas e lasanhas, a perda por reaquecimento também pode gerar uma série de problemas como amolecimento da massa e exsudação excessiva no prato pronto.

Conforme os resultados mostrados na Tabela 3, pode-se notar que conforme o esperado, tanto a presença de amido quanto de carragena interferem diminuindo a liberação de solução aquosa do produto, concordando com Hachmeister e Herald (1998), que afirmaram que perdas por cozimento de embutidos de peru foram afetadas significativamente com a adição de alguns hidrocolóides.

Dentre os ingredientes, e nas concentrações testadas, a amostra adicionada de amido e carragena [experimento 1 $(\mathrm{A}+\mathrm{C})$ ] apresentou os menores valores percentuais, tanto para perda por resfriamento $(0,91 \%)$ quanto para perda por reaquecimento $(10,61 \%)$.

Além das interpretações individuais dos resultados, por intermédio do experimento fatorial $2^{2}$, é possível prever o comportamento dos produtos e medir o efeito da utilização de um determinado ingrediente, bem como a interação entre eles em toda a faixa avaliada.

Ainda pela Tabela 3 é possível verificar os efeitos significativos do experimento $(\mathrm{p}<0,05)$, que para a perda por reaquecimento se apresentou significativo tanto para o amido quanto para a carragena, ambos negativos, demonstrando-se que como esperado, quanto maior a concentração de amido ou de carragena, menor é a perda por resfriamento e conseqüentemente maior o rendimento do produto (absorção de água).

A carragena, mesmo a $1 \%$, apresentou melhor comportamento para a perda por resfriamento de produto, revelando um efeito negativo $(-3,780)$; estes dados concordam com aqueles encontrados por Lyons et al. (1999). Há concordância também com Daigle et al. (2005), que estudando produto curado de carne PSE de peru, afirmaram que carragena a $0,75 \%$ melhora a funcionalidade de proteínas, e para maximizar este efeito kappa-carragena pode ser misturada à iota-carragena para evitar sinérese. Neste mesmo experimento, a adição de apenas 0,3\% de carragena não apresentou diferença significativa de perda por cozimento em relação àquela amostra elaborada com carne de peru normal, devido ao baixo nível de carragena utilizado.

Entretanto, para a perda por reaquecimento, o produto adicionado de amido obteve um índice mais baixo $(-8,619)$ que o da carragena $(-6,098)$, sugerindo que a matriz do amido (amido de mandioca) apresenta boa estabilidade ao cozimento retendo a água no produto. Os resultados são concordantes com aqueles encontrados por Hughes, Mullen e Troy (1998), que afirmaram que a adição de amido de mandioca e proteína de soro de leite diminuiu significativamente a perda por cozimento, e com Seabra et al. (2002), que avaliando hambúrgueres de carne ovina com teores reduzidos de gordura, adicionados de amido de mandioca ou farinha de aveia, detectaram que estes apresentaram melhor rendimento na cocção e melhor capacidade de retenção de água.

Os produtos sem adição de polissacarídeos apresentaram os maiores valores tanto para perda por resfriamento quanto para perda por reaquecimento, concordando com Hamchmeister e Herald (1998); os autores, avaliando embutidos de peru, verificaram que o maior índice de perda ocorreu no padrão sem adição de hidrocolóide, e os de menores índices foram encontrados nos adicionados de amido de mandioca e de amido de milho ceroso intercruzado. O mesmo resultado foi constatado para a perda por reaquecimento.

O efeito secundário ou de interação de amido e carragena $(1 \times 2)$ mostrou-se não significativo $(\mathrm{p}>0,05)$ para a perda por resfriamento, contudo quando as amostras foram avaliadas quanto às perdas por reaquecimento, tanto os efeitos primários quanto os secundários mostraram-se significativos $(\mathrm{p}<0,05)$, revelando que a utilização tanto de amido quanto de carragena mostram-se como importantes redutores de perda de água.

Na Figura 1, é possível notar que os mais altos valores de perdas por cozimento apresentam-se na região de níveis negativos $(-1 ;-1)$, portanto, sem adição de amido ou de carragena dentro dos níveis estudados. Os resultados mostram a perda por reaquecimento de produtos elaborados segundo planejamento experimental.

$\mathrm{Na}$ Figura 2, o gráfico de perda por reaquecimento, segundo experimento fatorial, revela o ponto de maior perda na região do mínimo dos dois efeitos primários, mostrando que conforme esperado, os produtos com níveis mais baixos de amido e carragena apresentaram mais altos valores de perda por reaquecimento.

As amostras adicionadas de carragena no seu nível alto, com ausência de amido (experimento 2) apresentaram o problema de formação de um exsudado gelatinoso, concordando com a citação de Bater, Decamps e Maurer (1992) de que produtos cárneos com adição de carragena apresentam a formação deste exsudado com elevada umidade.

No presunto de peru, a adição de amido de mandioca, mesmo em seu nível alto (experimento 3), não apresentou este

Tabela 3. Resultados dos efeitos do planejamento experimental (perda por resfriamento e reaquecimento e análise de textura).

\begin{tabular}{|c|c|c|c|c|c|c|c|c|c|c|c|c|}
\hline \multirow[t]{2}{*}{ Efeitos } & \multicolumn{3}{|c|}{ Perda por resfriamento } & \multicolumn{3}{|c|}{ Perda por reaquecimento } & \multicolumn{3}{|c|}{ Compressão } & \multicolumn{3}{|c|}{ Força de cisalhamento } \\
\hline & Efeito & CV\% & $\mathrm{p}$ & Efeito & $\mathrm{CV} \%$ & $\mathrm{p}$ & Efeito & $\mathrm{CV} \%$ & $\mathrm{p}$ & Efeito & $\mathrm{CV} \%$ & $\mathrm{p}$ \\
\hline Média/interação & 2,848 & 0,42 & $0,000^{*}$ & 16,271 & 0,517 & $0,000^{*}$ & 4,855 & 0,087 & $0,000^{*}$ & 12,539 & 0,54 & $0,000^{*}$ \\
\hline (1) Amido & $-3,435$ & 1,071 & $0,011^{*}$ & $-8,619$ & 1,267 & $0,000^{*}$ & $-0,263$ & 0,216 & 0,227 & $-1,265$ & 1,322 & 0,346 \\
\hline (2) Carragena & $-3,78$ & 1,071 & $0,006^{*}$ & $-6,098$ & 1,267 & $0,000^{*}$ & $-0,466$ & 0,216 & $0,035^{*}$ & $-0,613$ & 1,322 & 0,646 \\
\hline $1 \times 2$ & 1,41 & 1,071 & 0,221 & 3,107 & 1,267 & $0,028^{*}$ & 0,181 & 0,216 & 0,404 & 0,972 & 1,322 & 0,467 \\
\hline
\end{tabular}

*efeito significativo. 
Superficie ajustada: variável: perda por cozimento experimento $2^{2}$
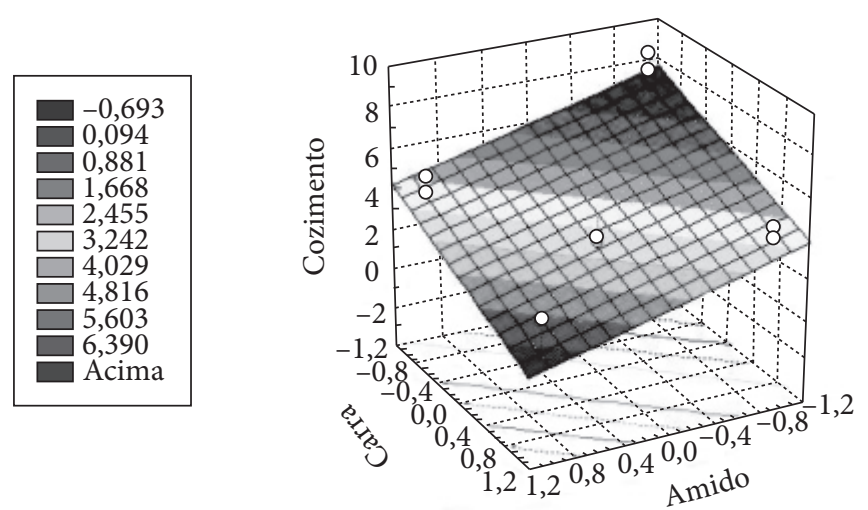

$z=2,8484615384615-1,7175 * x-1,89 * y+0$

Figura 1. Gráfico de superfície para perda por cozimento dos presuntos de peru em função das quantidades de amido e carragena adicionados.

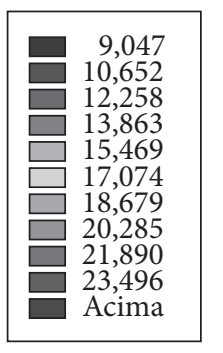

\author{
Superfície ajustada: \\ variável: perda por reaquecimento \\ experimento $2^{2}$
}

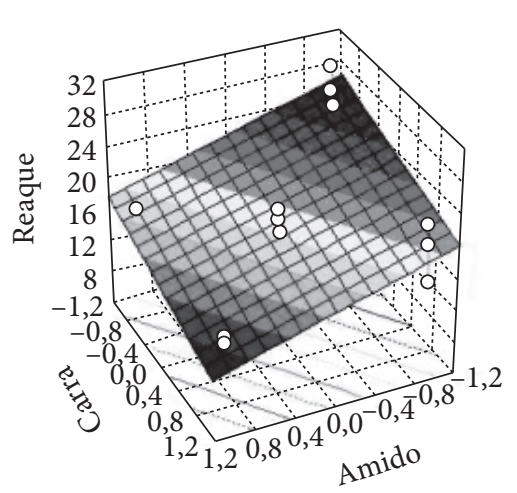

$$
\mathrm{z}=16,271257538867-4,3094698788654
$$$$
{ }^{\star} \mathrm{x}-3,0488144468899{ }^{\star} \mathrm{y}+0
$$

Figura 2. Gráfico de superfície para os resultados de perdas por reaquecimento de presuntos de peru com diferentes níveis de amido e carragena.

efeito, além disso naquela amostra que apresentava o nível alto de carragena e o nível alto de amido (experimento 1), o problema não foi constatado, indicando que o amido de mandioca apresenta uma característica de evitar a exsudação que ocorreu na amostra produzida apenas com a adição da carragena.

\subsection{Textura instrumental}

Os resultados das análises de textura estão apresentados na Tabela 3. Nos testes de compressão, a carragena apresentou um efeito significativo negativo $(\mathrm{p}<0,05)$, indicando que a utilização neste nível confere ao produto redução na força de compressão, provavelmente em virtude de o produto agregar mais água. Esta afirmação discorda daquela de Pietrasik (2003), que constatou que amostras de produtos cárneos, preparados com kappa-carragena tiveram um aumento substancial de dureza. Além disso, a carragena interage com proteínas para melhorar rendimento e textura em produtos de carnes de aves, especialmente quando altos níveis de água são utilizados.

Hachmeister e Herald (1998) constataram que amido modificado pode acentuar a firmeza e outras características texturais em produtos de teor reduzido de gordura (produtos emulsionados de peru adicionados de água).

Não foram observadas diferenças significativas quanto aos valores de força de cisalhamento para os presuntos de peru elaborados sem nenhum dos polissacarídeos testados (amido ou carragena) ao contrário dos valores obtidos por Lyons et al. (1999), que relataram um efeito positivo de interação em relação à força de cisalhamento, quando amido de mandioca foi utilizado com o gel formado por carragena e concentrado protéico de soro de leite, o que segundo os autores pode ser explicado pela alteração da estrutura do gel depois do resfriamento.

\subsection{Cor dos produtos e atividade de água}

Avaliações de cor das amostras em colorímetro foram realizadas a fim de constatar a influência do polissacarídeo nesta característica física. Os dados são mostrados na Tabela 4. Os resultados mostram que os valores de efeitos não foram significativos para $\mathrm{L}^{*}$ e para $\mathrm{a}^{*}$. Para os valores de $\mathrm{b}^{*}$, somente $\mathrm{a}$ carragena apresentou efeito significativo $(\mathrm{p}<0,05)$. Contudo, nas concentrações de carragena avaliadas por Pietrasik (1999), observou-se que ingredientes não cárneos influenciaram os parâmetros de cor para os produtos avaliados, mas que a adição de carragena gerou produtos com valores mais baixos de $\mathrm{L}^{*} \mathrm{eb}^{*}$ e mais altos de $\mathrm{a}^{\star}$. A presença de carragena, de maneira geral, resultou em produtos mais escuros quando comparados com aqueles sem esta adição.

Ainda na Tabela 4, é possível notar que os valores de atividade de água $(\mathrm{Aa})$ mostram que dentro dos níveis estudados houve um efeito significativo negativo para a carragena $(-0,003)$, indicando que quanto maior a quantidade de carragena adicionada ao produto menor a atividade de água. Este resultado é interessante do ponto de vista da estabilidade microbiológica do produto. Os valores para amido não foram significativos nas concentrações utilizadas.

\subsection{Análise sensorial}

\section{Aceitabilidade}

As amostras de presunto de peru, segundo o teste de escala hedônica, não apresentaram diferenças significativas quanto à aceitabilidade $(\mathrm{p}>0,05)$. A média de todas as amostras revelou notas entre 6 e 7 (gostei ligeiramente/gostei moderadamente).

Apesar da análise de escala hedônica não apontar diferenças entre características das amostras, é possível considerar que todas as amostras produzidas, independentemente da quantidade de amido ou carragena adicionados foram bem aceitas pelos 
provadores. Isso está de acordo com o trabalho de Daigle et al. (2005), que realizaram análise sensorial em produtos cárneos fabricados com carne PSE de peru e adição de hidrocolóides como carragena, colágeno e proteína de soja e não detectaram diferenças sensoriais $(p>0,05)$ entre todos os tratamentos. Os autores utilizaram escala hedônica de 9 pontos, cujas médias reveladas para todos os tratamentos estiveram entre 6 e 7 (gostou ligeiramente e gostou moderadamente). Os autores demonstraram que a adição de carragena, proteína de soja e colágeno $(0,3,1,5$ e $1,5 \%$, respectivamente) não afetaram a aceitação dos consumidores.

Sampaio et al. (2004), avaliando salsichas com substituição de gordura, concluíram que na avaliação sensorial quanto à aceitabilidade, amido de mandioca, carragena e o controle não apresentaram diferenças significativas, enquanto que a amostra com proteína de trigo apresentou aceitabilidade abaixo de $50 \%$.

Seabra et al. (2002), estudando hambúrgueres com substituição de gordura por amido de mandioca e farinha de aveia, não constataram diferenças significativas entre as amostras, tanto para aceitação global do produto quanto para atitude de compra. Isto demonstra que a redução de gordura dos produtos não foi detectada pelos consumidores, independente da utilização dos substituintes.

Alguns trabalhos descrevem adição de polissacarídeos como favoráveis sensorialmente como o de Lyons et al. (1999). Os autores afirmaram que a adição de amido de mandioca a seco revelou um efeito positivo nos parâmetros sensoriais e físicos de salsichas com baixo teor de gordura.

Escala do ideal de cor (just right scales)

e intenção de compra

A amostra de presunto de peru com $1 \%$ de amido e $0,5 \%$ de carragena (Nível 0) foi submetida ao teste de avaliação de cor e intenção de compra. Quanto à avaliação de cor, os resultados são mostrados na Tabela 5 .

Desta forma, verificou-se que o produto apresentou uma divisão de opiniões quanto à cor, o que se deve provavelmente à preferência pessoal de cada consumidor. É uma opinião individual e cada um tem um padrão interno de aceitabilidade para cada produto.

Os dados de intenção de compra confirmam a boa aceitação do produto pelos consumidores. O perfil dos provadores está mostrado na Tabela 6 .

\section{Conclusão}

A utilização tanto de amido de mandioca quanto de carragena, nos teores estudados, melhorou características como retenção de água e perda de água por reaquecimento, contudo, sem apresentar diferenças significativas para características como cor (sensorial), atividade de água, textura e características de aceitação sensorial.

O sinergismo entre o amido e a carragena mostrou ser uma vantagem na tecnologia do produto, pois reduziu a formação
Tabela 5. Resultados de análise sensorial de presunto cozido de peru.

\begin{tabular}{lclc}
\hline \multicolumn{1}{c}{ Just right scales } & $\begin{array}{c}\text { \% de } \\
\text { respostas }\end{array}$ & \multicolumn{1}{c}{ Intenção de compra } & $\begin{array}{c}\% \text { de } \\
\text { respostas }\end{array}$ \\
\hline $\begin{array}{l}\text { Ligeiramente mais } \\
\text { escura que o ideal }\end{array}$ & 44 & $\begin{array}{l}\text { "Certamente compraria o } \\
\text { produto" }\end{array}$ & 58 \\
$\begin{array}{l}\text { Cor ideal } \\
\begin{array}{l}\text { Ligeiramente mais } \\
\text { clara que o ideal }\end{array}\end{array}$ & 22 & $\begin{array}{l}\text { "Provavelmente compraria" } \\
\text { "Talvez comprasse, talvez }\end{array}$ & 32 \\
não comprasse" & 10 \\
\hline
\end{tabular}

Tabela 6. Perfil dos provadores de análise sensorial de presunto cozido de peru.

\begin{tabular}{lclc}
\hline \multicolumn{1}{c}{ Sexo } & $\begin{array}{c}\text { Provadores } \\
(\%)\end{array}$ & \multicolumn{1}{c}{ Freqüência de consumo } & $\begin{array}{c}\text { Respostas } \\
(\%)\end{array}$ \\
\hline Homens & 68,8 & Consomem até 10x por mês & 53,1 \\
Mulheres & 31,2 & Consomem de 10 a 20x por mês & 34,3 \\
& & Consomem mais de 20x por mês & 12,5 \\
\hline
\end{tabular}

do exsudado gelatinoso presente na amostra que continha $1 \%$ de carragena.

Os resultados mostram que as amostras estudadas não apresentaram diferença significativa de aceitabilidade $(p>0,05)$ e a amostra que apresentou maior média (experimento 5 - ponto central) foi a que continha $1 \%$ de amido e $0,5 \%$ de carragena, sendo que para esta amostra os provadores entrevistados responderam que certamente comprariam o produto, o que indica um resultado bastante positivo.

Com base nos resultados obtidos, o amido pode ser um ingrediente interessante na formulação de presunto de peru, pois proporciona uma série de vantagens tecnológicas sem prejuízos às principais características sensoriais, além de reduzir custos. Há também a necessidade de se avaliar a questão legal referente à permissão da adição de amido em presunto, ou a criação de uma nova classe de produtos, na qual esta adição seja permitida.

\section{Agradecimentos}

Os autores agradecem à empresa Perdigão Agroindustrial S.A. e à Universidade Estadual de Ponta Grossa, pelo apoio a este trabalho, bem como à Universidade Estadual de Londrina/Departamento de Ciência e Tecnologia de Alimentos, pela possibilidade de utilização do texturômetro.

\section{Referências bibliográficas}

ABNT. Associação Brasileira de Normas Técnicas. NBR 14141: escalasutilizadas em análise sensorial de alimentos e bebidas. Rio de Janeiro, 1998.

AGRODIÁRIO. El jamón cocido debe ser jamón cocido. Disponível em: <http:// www.agrodiario.com.ar/index2003-08-28.htm> . Acesso em: 28 jan. 2005.

BATER, R.; DECAMPS, O.; MAURER, A. J. Quality characteristics of hidrocolloids added oven roasted turkey breasts. Journal of Food Science, Chicago, v. 57, n. 5, p. 1068-1070, 1992.

BRASIL. Ministério da Saúde. Secretaria de Vigilância Sanitária. Portaria $\mathrm{n}^{\circ} 27$, de 13 de janeiro de 1998. Regulamento técnico referente a informação nutricional complementar. 1998a. 
Vigilância Sanitária. Portaria no 1004 de 11 de dezembro de 1998. Atribuição de função de aditivos e seus limites máximos de uso para a Categoria. Carnes e produtos cárneos. [s. l: s. n.], 1998 b.

. Ministério da Agricultura. Regulamento Técnico de Identidade e Qualidade de Almôndega, de Apresuntado, de Fiambre, de Hambúrguer, de Quibe, de Presunto Cozido. Diário Oficial, Brasília, n 149, seção 1, p. 7-12, 2000.

CAI, W.; XUE, Z. Property and application of complex gel of xanthan gun and k-carrageenan to ham. Shipin Gongye Keji, Beijing, v. 21, n. 3, p. 15-18, 2000.

CARRAGENA, um alimento indispensável! Aditivos Ingredientes. São Paulo: Insumos, n. 6, p. 22-32, 2000.

DAIGLE, S. P. et al. PSE-like turkey breast anhancement throug adjunct incorporation in a chunked and formed deli roll. Meat Science, Oxford, v. 69, n. 2, p. 319-324, 2005.

DEMiATE, I. M.; KONKEL, F. E.; PEDroso, R. A. Avaliação da qualidade de amostras comerciais de doce de leite pastoso - composição química. Ciência e Tecnologia de Alimentos, Campinas, v.21, n.1, p.108 -114, 2001.

FERREIRA, V. L. P. et al. Análise Sensorial - Testes Discriminativos e Afetivos. Campinas : Profiqua/SBCTA, 2000. 127 p. (Manual: Série Qualidade).

HACHMEISTER, K. A.; HERALD T. J. Thermal and rheological properties and textural attributes of reduced-fat turkey batters. Poultry Science, Savoy, v. 77, n. 4, p. 632-638. 1998.

HUGHES, E.; MULLEN, A. M.; TROY, D. J. effects of fat level, tapioca starch and whey protein on frankfurters formulated with $5 \%$ and 12\% fat. Meat Science, Oxford, v. 48, n. 1-2, p. 169-180, 1998.

KANBE, T. et al. Nutritional analysis of the pressed hams graded according to the JAS. Seikatsu Eisei, Osaka, v. 3, n. 23, p. 43-48. 1979.

LABELL, F. Modiefied tapioca starches provide smoother textures (Brief article). Disponível em: <http://www.findarticles.com/p/ articles/mi_m3289/is_3_169/ai_61759522> Acesso em: 22 jul. 2004.
LANARA. Laboratório Nacional de Referência Animal. Métodos analíticos oficiais para controle de produtos de origem animal e seus ingredientes - Métodos físico-químicos. Brasília, 1981.

LYONS, P. H. et al. The influence of added whey protein/carrageenan gels and tapioca starch on the textural proprieties of low fat pork sausages. Meat Science, Oxford, v. 51, n. 1, p. 43-52, 1999.

NABESHIMA, H. E. Amidos modificados em produtos cárneos de baixo teor de gordura. Higiene Alimentar, São Paulo, v. 12, n. 54, p. 36-41, 1998.

PIETRASIK, Z. Effect of content of protein, fat and modified starch on binding textural characteristics, and color of comminuted scalded sausages. Meat Science, Oxford, v. 51, n. 1, p. 17-25, 1999.

Binding and textural proprieties of beef gels processed with $\mathrm{k}$-carrageenan, egg albumin and microbial transglutaminase. Meat Science, Oxford, v. 63, n. 3, p. 317-324, 2003.

SAMPAIO, G. R. et al. Effect of fat replacers on the nutritive value and acceptability of beef frankfurters. Journal of Food Composition and Analysis, Oxford, v. 17, n. 3-4, p. 469-474, 2004.

SEABRA, L. M. et al. Fécula de mandioca e farinha de aveia como substituinte de gordura na formulação de hambúrguer de carne ovina. Ciência e Tecnologia de Alimentos, Campinas, v. 22, n. 3, p. 245-248, 2002.

SENASA. El jamón cocido debe contener solo carne de cerdo. Diponível em <http://www.senasa.gov.ar/dinamicas/prensa/ muestra.php?id=18690>. Acesso em: 28 jan. 2005.

USA, Federal Register. Use of soy protein concentrate, Modified Food Starch, and Carrageenan as Binders in Certain Meat Products. Washington DC, v. 64, n. 99, 1999.

YANG, A. et al. Evaluation of some binders and fat substitutes in lowfat frankfurters. Journal of Food Science, Chicago, v. 66, n. 7, p. 1039-1046, 2001.

WURLITZER, N. J.; SILVA, A. T. Uso de farinhas de arroz como substituto de féculas de mandioca em apresuntado. Ciência e Tecnologia de Alimentos, Campinas, v. 15, n. 2, p. 118-123, 1995. 